\title{
Teaching sustainable development in materials science and engineering
}

\author{
R. LeSar, K.C. Chen, and D. Apelian
}

\begin{abstract}
Preparing the next generation of materials scientists and engineers requires more than teaching them knowledge of material properties and behaviors. Materials science and engineering must also take into account materials sustainability in the context of society and the environment, as discussed throughout this issue. Including topics such as sustainability in a materials curriculum is not new. Issues of ethics, costs, and so on have long been an integral part of our education. Although detailed treatment of all such topics cannot be included in a general materials education curriculum, the concepts of sustainable development and the role of materials in a sustainable future can be introduced. Indeed, many materials science programs are beginning to include these topics in their curricula. This article discusses three such programs that the authors have helped design and implement in the United States, each taking a different approach to engaging students in these topics. The intention is not to provide an exhaustive overview of education in sustainable development, but rather to describe a range of strategies that are currently being applied and to raise pertinent issues in materials science education.
\end{abstract}

\section{Introduction}

The challenges of sustainable development will require materials engineers and scientists to think beyond the current definition of what constitutes the "best" material for a given application. Increasingly, considerations of issues such as resources, toxicity, and life cycles will also be necessary. The question for engineering faculty is how to prepare students to meet these challenges. In this article, we describe some ways in which our separate institutions are currently teaching sustainable development to engineering students, especially materials scientists and engineers. Rather than providing a comprehensive review, we focus on three programs that can serve as examples of various pedagogical approaches. Before discussing these examples, however, we review some concepts that provide a basis for understanding sustainable development in a broader context.

The first step in designing a curriculum in sustainable development is to agree on a common definition of what is meant by the term. As noted in the introductory article to this issue, the United Nations' Brundtland Commission defined sustainable development as development that "meets the needs of the present without compromising the ability of future generations to meet their own needs." Such a definition yields a broad and flexible starting point for discussion. The advantage of a broad definition is that it does not restrict sustainable development to mean any specific technological or environmental topic but rather includes all current activities that could affect future generations. Thus, the definition can be refined accordingly for a specific course or project.

In the most general sense, the goal of sustainable development is to create a sustainable global society, where society is viewed as a system. In the simplest version of this view, often called the "triple bottom line," a society is considered as the union of environmental, economic, and social (cultural) systems, ${ }^{2,3}$ that is, a system of rather complex subsystems.

A sustainable society is thus one that meets societal needs while maintaining the integrity of the environment and ecosystems, the economy, and the social needs of individuals. Thinking of a society as a system is essential, because it implies that optimization of the system as a whole will not generally entail optimization of the individual subsystems; rather, tradeoffs between the constituent components are the norm. Thus, traditional linear, sequential optimization strategies are inadequate. Moreover, given the complexity and nonlinearity of the interactions among the components, society is a complex system exhibiting emergent behavior that is not generally obvious from 
the properties of its processes and parts. Consequently, the optimal technological solution in any situation might not be the best solution for society as a whole.

A course in sustainable development must thus teach students to recognize that engineering operates in a broad societal context and to take that context into account. This view is easily incorporated into the classic definition of engineering as "design under constraint," as sustainable development (in the broad sense discussed above) simply creates a new set of constraints. Indeed, future physical constraints on technology will be increasingly stringent with, for example, growing energy costs and requirements for low emissions of greenhouse gases. Equally demanding will be the societal and economic constraints. These additional constraints will require a different way to think about technology.

More specifically, these constraints might include limited availability of some materials, arising from their natural distribution in the lithosphere or from geopolitical forces, materials toxicity, and the like. Resource limitations will likely require the replacement of materials, as well as the design of products for enhanced recyclability. The issues facing specific technologies, including materials, however, are all based on the basic system-level concepts of sustainable development described above.

The question, then, is how one introduces students to these ideas about sustainable development. Because sustainable development is a relatively new topic in higher education, there is no standard curriculum, and a great variety of approaches could be taken. Herein, we highlight three approaches that range from a common course for all first-year students to an integrated set of courses to an entirely revamped curriculum that incorporates sustainable development throughout as a central theme. Although all programs have their own constraints and many other universities are working to establish such programs, it is our hope that these few examples will prompt discussion and generate new ideas.

\section{Teaching sustainable development at Worcester Polytechnic Institute (WPI)}

WPI started teaching sustainability-related courses for firstyear students in 2007, in a series called the Great Problems Seminars. ${ }^{5}$ The first courses were called "Power the World" and "Feed the World." The Great Problems Seminars were conceived to immerse first-year students in societal issues and to inspire and engage them. They are offered to students in all fields (life sciences, humanities, business, and engineering), and as of 2010 , about $40 \%$ of the first-year students opted to enroll. At present (2011-2012 academic year), discussions about making the courses mandatory are ongoing.

In the development of this program, the faculty established several objectives:

- to encourage critical thinking, information literacy, and evidence-based writing;

- to engage first-year students with current events, societal problems, and human needs;
- to cultivate in each student a personal foundation for lifelong learning;

- to contribute to a more intellectually stimulating environment at WPI; and

- to promote civic engagement and community partnerships. In addition, an interdisciplinary team (Engineering, Humanities and Arts) developed a course called "Sustainable Development for the 21st Century-Making Our World" that has been offered every year since 2008. This course emphasizes the role of materials science and engineering (MSE) as a vehicle for addressing many of the societal issues related to sustainable development, rather than focusing solely on the study of the physical and chemical nature of solids. Specifically, students learn about society's burgeoning needs in the areas of energy resources, mobility/transportation, housing, food and water, resource recovery/recycling, and health care, not to mention climate change and environmental issues, and see how materials science is intertwined with each of these societal issues. The course thus provides a much larger and holistic context for MSE.

During the first part of each of the above courses (a sevenweek period), students form teams of three or four and study the basic facts, write essays, and participate in active discussions on the above-mentioned societal issues, from both technical and public-policy perspectives. During the second part of the course, the student teams work on a specific project addressing one of these topics. At the end of the course, the teams present their work in a public forum, write a final report, and make a poster that is judged externally.

Each course is designed to have the students grapple with real-world problems and develop skills of rigorous analysis, active engagement, and creative synthesis. They develop communication skills to pursue inquiry-based work, to make connections between disciplines, to explore current events and issues, and to consider the broader implications of science and technology. Specifically, the aim is for students to

- learn about the concepts of sustainable development, climate change, energy sources, food and water issues, health concerns, and housing and transportation needs at the start of the 21 st century in terms of both the MSE issues and the human/social aspects;

- approach these issues proactively with an eye toward ecologically sound solutions;

- experience the value of engaging different disciplinary perspectives - from materials science to statistics, environmental studies, history, and philosophy — in addressing real-life problems;

- learn to formulate researchable questions based on multiple sources; and

- participate in classroom debates and discussions on complex issues of sustainable development and contribute to teamwork. The students in these courses have learned that sustainable development in the 21 st century is attainable and that it will require innovation and the will to effect change. Some of the students have taken these lessons much further afield, with projects in Kenya on water systems and soap making, for example (Figure 1). 
In 2008, The National Academy of Engineering (NAE) commissioned a study titled Changing the Conversation: Messages for Improving Public Understanding of Engineering. ${ }^{6}$ The resulting report recommends that the engineering community begin immediately to plan and initiate a coordinated communications campaign to interest young people from all backgrounds in engineering careers by appealing to their desire to find hands-on solutions to problems that can make a difference in the world and improve people's lives. The courses at WPI are very much in line with the recommendations of this report.

\section{Teaching sustainable development at lowa State University}

The Materials Science and Engineering Department at Iowa State University has partnered with the Mechanical Engineering Department to develop a series of three interrelated courses on sustainable development that incorporate a systems-level view, rather than centering on specific disciplines. The focus of these courses is, in part, on the developing world, largely because the systems there tend to be somewhat less complex and more amenable to analysis. Care is taken, however, to emphasize how these ideas also apply to the developed world.

Taken as a whole, these courses consider a wide range of technical and societal issues, with the balance between "engineering" and "context" varying between the classes. Although the courses constitute an interconnected set, linking to and supplementing each other, they are independent and can thus serve the needs of a broad group of engineering students.
The course "Sustainable Engineering for International Development" is specifically geared toward presenting descriptions of society and communities as systems and providing a broad view of sustainable development and appropriate technology to develop a picture of water, energy, and materials issues in communities at all stages of development. Although predominantly technical, this course contains a significant focus on economics, anthropology, and other topics. Materials make up a large part of the class, with discussions on resource sustainability and how one chooses materials for specific sustainable technologies. Typically, around 30 students take this class.

The Mechanical Engineering course "Design for Appropriate Technology" offers a new take on the senior design course, with a focus on creating appropriate solutions for specific applications in the developing world. Students are asked to respond to defined needs of people in a poor village in Africa. They have access to both previous designs and assessments of how well those designs have worked in a practical application. Although this course is predominantly technical, its problems are motivated within a societal context.

The final class in the sequence, "Applied Methods in Sustainable Engineering for International Development," is a summer study-abroad class taught in a small village in Mali, in western sub-Saharan Africa. ${ }^{7}$ The same village is visited each year, so projects implemented in one year can be assessed and improved in following years. Students spend three weeks in the village, in which most, if not all, villagers live on well under US\$1.25/day (designated as extreme poverty by the World Bank). The students implement projects in the village, some of which originate in the senior design course discussed above. Owing to the complexities of travel to Mali, this course can accommodate only 10-12 students at a time.

In this class, the use of materials is a critical part of the experience. In an isolated village with few resources, the students must rely on local materials, generally mud (for bricks and stoves), iron from the village blacksmith, and wood from the carpenter, to complete their projects. As an example, we introduced new cook stoves into the community, with the aim of reducing smoke and associated health hazards, as well as improving efficiency compared to open fires. These stoves were of a simple design, made of local materials, so that the villagers could manufacture their own stoves, as purchasing stoves is generally beyond their financial means. Over the first three years of the class, we first assessed the cooking needs of the village, which determined what form of stove to create, and then assessed, within the context of a wider-ranging evaluation of village energy needs, the effectiveness of the stove design. For example, Figure 2 shows a
Figure 1. Worcester Polytechnic Institute student Anna Chase (second from left) introducing women in the village of Malewa, Kenya, to the Better Water Maker (foreground). This portable device purifies water with ultraviolet light generated using a hand crank. Photo by D. Apelian. 
student learning how to separate grain as part of this assessment of energy and cooking needs.

One outcome of this experience is a realization of how materials dominate our technology, as well as an appreciation of how much one can do with some basic materials understanding. Another part of the assignment is to create a report on some specific social, economic, or environmental aspect of the village, to supplement the systems-level description. Students create these reports through data gathered, in part, by interviewing people in the village. Among the goals for this class is the creation of an environment in which students can learn how to work effectively in a culture that is very different from their own. The major goal, however, is to change how students view the role of engineering in society, enabling them to have a first-hand understanding of how context informs engineering solutions. The net result is also a change in how they view themselves as engineers.

It is also important to extend the discussion of sustainable development beyond engineering. To that end, Engineering and Economics faculty have co-created a course called "Globalization and Sustainability" that teaches a systems-level view of sustainable development and is open to all undergraduates. Taught in the "Technology and Social Change" program in the College of Liberal Arts and Sciences, this course includes students from all six undergraduate colleges and from all stages of their undergraduate experience, with enrollment of approximately 100 students. Materials make up an appreciable portion of this class, with a focus on the ubiquity of materials in technology, as well as the scarcity of some resources and how that scarcity can have an impact on future technological solutions for sustainable energy

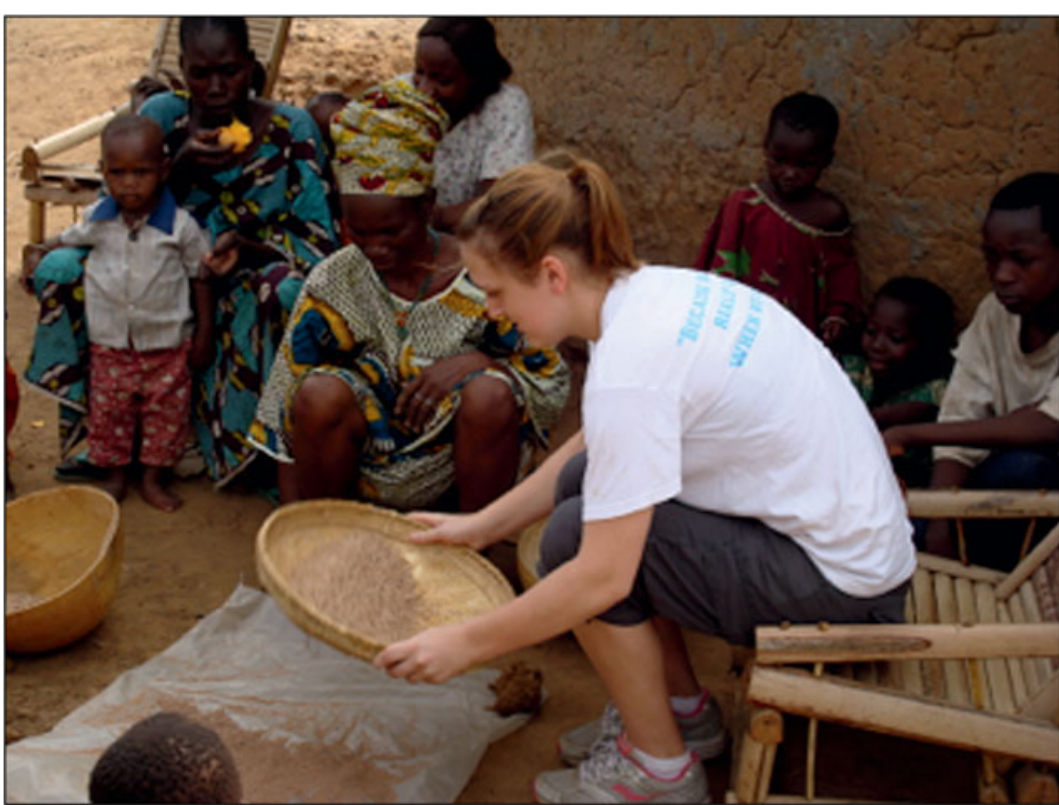

Figure 2. Student working with women in a village in Mali to help determine energy and cooking needs. Photo by R. LeSar. and products. This class is a core course in a new minor in sustainability.

\section{Teaching principles of sustainability at California Polytechnic State University}

The Materials Engineering department at the California Polytechnic State University ("Cal Poly"), San Luis Obispo, has taken the approach of infusing principles of sustainability throughout its entire curriculum. That is, awareness and considerations of the social and environmental impacts are interwoven within several courses and have a prominent place in the program's mission and culture. Through a National Science Foundation departmental-level reform grant awarded in 2006, the department collectively transformed its curriculum to embrace sustainability and project-based learning. ${ }^{8,9}$ Although basic principles of materials science and engineering are still at the core, there has been a shift in the approach — from scientific analysis to project-based engineering design with realistic constraints. Central tenets of the new curriculum include systems thinking and the role of engineers in society. Problems have been reframed to show interconnectedness and to give greater context (e.g., new alloy systems must be developed to replace toxic, lead-based solders yet still provide equal or better thermal and mechanical performance), in order to help develop engineers with the skills and mindset to effectively handle the complex, global issues of the future.

Sustainability themes are introduced in the freshmen year and continue throughout the students' program of study in different courses and from different perspectives. ${ }^{10}$ Firstyear students design, build, and test solar water heaters in the context of impoverished communities. They then perform a service-learning project with local community partners and learn about user needs, engineering design, communication, and project management. As an example, a team of students worked with a local charter elementary school that did not have any hot water for hand washing or science experiments. The Cal Poly students designed and installed a solar water system (Figure 3) and created associated learning materials about their design for the children. User-centered design places the focus on people and can be a great motivator for learning.

The second year includes the courses "Materials, Ethics \& Society" and "Materials Selection for the Life Cycle." CES Selector software with the Eco Audit too ${ }^{11}$ is employed to quantitatively assess the choices of different materials during different parts of the product life cycle. Students learn about the "triple bottom line" (as mentioned in the Introduction) and how the cost of a product involves many different factors such as labor, embodied energy, transportation, supply and demand, and politics (e.g., wars, 


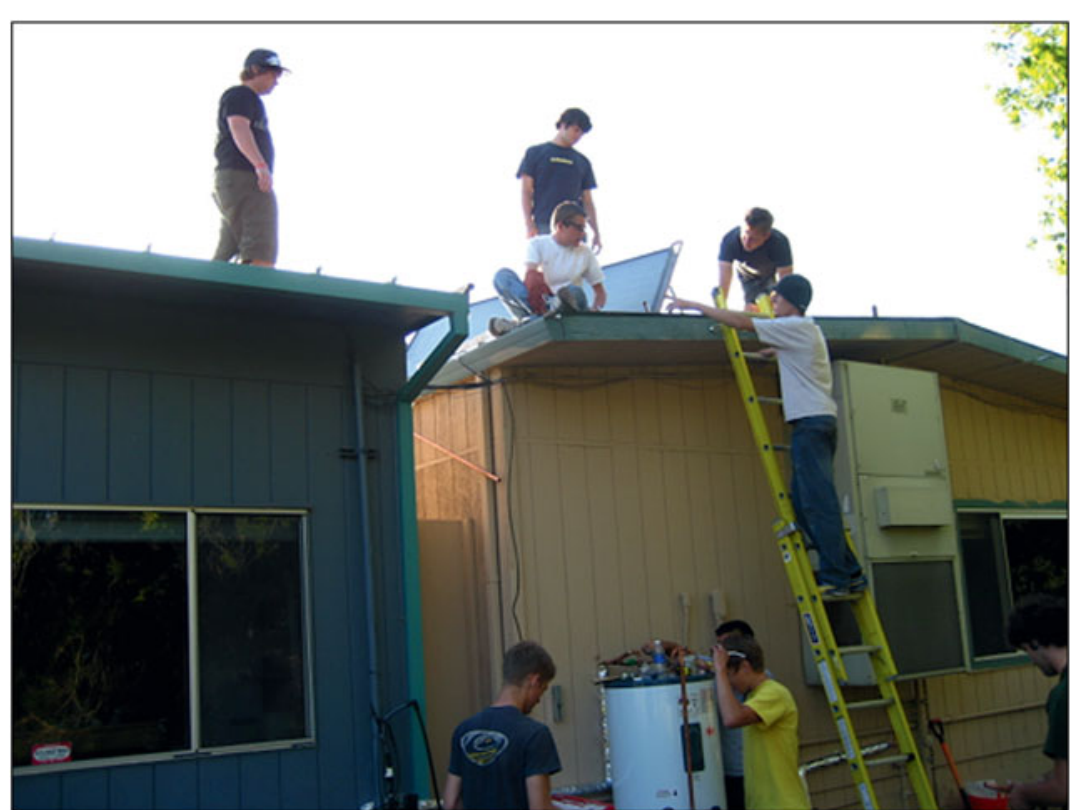

Figure 3. Freshman service learning project with a California K-6 charter school to install a solar water heater. Cal Poly students conducted a user needs assessment and identified the engineering design constraints and requirements to provide hot water to school children to wash their hands and for the science teacher to conduct experiments. They then installed the system and still maintain it. Photo by K. Chen. bioresins for surfboards, degradation of natural fiber composites, biochar as an energy source for developing countries), and several graduates have actively sought jobs in areas that pertain to sustainability (e.g., solar cells, electric vehicles).

\section{Where do we go from here?}

Thus far, this article has summarized our experiences in implementing educational programs in sustainable development at Worcester Polytechnic Institute, Iowa State University, and California Polytechnic State University. As we and others improve current courses and develop new learning opportunities in sustainable development, the central issue is how to provide the most meaningful and practical learning experiences for our students. Questions on the details of such programs remain, such as:

- How should specialization in the materials field be balanced with broader, multidisciplinary education?

- How can different universities share their experiences in teaching sustainable development?

strikes, and embargos). Current news articles are used to emphasize the topics' relevance, and directed reflection assignments and in-class discussions allow greater opportunity for thought on the impact of engineering on people and the planet. For example, an assignment that has a significant impact on students is a set of articles and photo gallery ${ }^{12}$ on the electronic wastes that end up in developing countries. Students make the connection between their latest cell phone and young children exposed to toxic materials in other parts of the world. Likewise, the connection between the demand for rare-earth metals for renewable energy technologies and the devastation of farmland in $\mathrm{China}^{13}$ requires broader views and systems thinking.

Processing, structure, and properties of materials find new context in appropriate technology. For example, discussion of the organization Potters for Peace (http://www.pottersforpeace. org/) provides great context for considering purposeful porosity in ceramics to filter water. Similarly, an introduction to the European RoHS regulations (Restriction of the Use of Certain Hazardous Substances in Electrical and Electronic Equipment) and the search for lead-free solders drives the need to understand eutectic alloy systems and phase diagrams. Real-world contexts and realistic design constraints that involve environmental and societal impacts provide rich learning experiences for students.

Experience at Cal Poly has shown that students become more invested in their learning when topics relate to the "real world" and when engineering offers solutions to global problems. More students in this program are also choosing senior projects that have a sustainability theme (e.g.,
- What types of data should be collected to assess the teaching of sustainable development? (e.g., How does one assess student ability to "systems think"?)

- How can these programs impact all materials science students and encourage all practitioners to embrace sustainable development as part of our profession?

We feel that a clearinghouse or forum for educators to share ideas and experiences around the teaching of sustainable development would be beneficial for our community. Perhaps the University Materials Council, an organization of U.S. and Canadian materials science educators that serves as a forum for sharing best practices and discussing issues such as curricular improvements (http://www.umatcon.org/), could take the lead in this domain.

\section{Summary and conclusions}

The educational system is still in the beginning stages of learning how to teach a broader view of sustainable engineering. In addition to the three institutions profiled, many other universities have also been developing new curricula and research based on these ideas, and indeed, a few have created centers focused on these issues. ${ }^{14-16}$ The key point for all materials scientists is that the solutions that are being proposed for sustainable development, including green designs, renewable energy, and a host of others, cannot meet our future challenges unless we find appropriate technologies and paths for our society and ourselves. Our job in the university is to ensure that we turn out scientists and engineers who are best prepared to do so. 


\section{References}

1. Report of the World Commission on Environment and Development: Our Common Future (Annex to Document A/42/427, Oxford University Press, Oxford, UK, 1987).

2. W.M. Adams, The Future of Sustainability: Re-thinking Environment and Development in the Twenty-first Century (International Union for Conservation of Nature, Gland, Switzerland, 2006).

3. S. Dodds, Ecol. Econ. 23, 95 (1997).

4. W.A. Wulf, in Issues in Science and Technology Online (University of Texas at Dallas, Richardson, TX, 1998), www.issues.org/15.2/wulf.htm (accessed November 2009).

5. Undergraduate Studies: Great Problems Seminars (GPS), http://www.wpi.edu/ academics/Undergraduate/FirstYear/gps.html.

6. Changing the Conversation: Messages for Improving Public Understanding of Engineering (National Academy of Engineering, Washington, DC, 2008).

7. R. LeSar, K.M. Bryden, "Study Abroad Experiences in the Developing World: Opportunities and Challenges," in Mater. Res. Soc. Symp. Proc. 1320 (Materials Research Society, Warrendale, PA, 2011).

8. L. Vanasupa, K.C. Chen, J. Stolk, R.N. Savage, T.S. Harding, B. London, W.L. Hughes, "Converting Traditional Materials Labs to Project-based Learning Experiences: Aiding Students' Development of Higher-order Cognitive Skills," in Mater. Res. Soc. Symp. Proc. 1046 (Materials Research Society, Warrendale, PA, 2007).
9. L. Vanasupa, K.C. Chen, F. Splitt, J. Mater. Educ. 28 (3-6), 171 (2006). 10. K.C. Chen, L. Vanasupa, B. London, R.N. Savage, "Infusing the Materials Engineering Curriculum with Sustainability Principles," in Proc. 2006 Am. Soc. Eng. Educ. Annu. Conf. (ASEE, Washington, DC, 2006), paper 2006-378.

11. Granta CES 2012 Selector (Granta Design Ltd., Cambridge, UK), www. grantadesign.com/products/.

12. "China's Electronic Waste Village," Time Magazine (7 January 2009), www. time.com/time/photogallery/0,29307,1870162,00.html.

13. "Earth-Friendly Elements, Mined Destructively," New York Times (26 December 2009), p. A1.

14. Center for Sustainable Engineering, a partnership among Syracuse University (lead institution), Arizona State University, Carnegie-Mellon University, Georgia Institute of Technology, and the University of Texas at Austin supported by the National Science Foundation and the Environmental Protection Agency, www.csengin.org (accessed November 2009).

15. International Sustainable Engineering Initiative, Civil and Environmental Engineering Department, Michigan Technical University, www.cee.mtu.edu/ sustainable_engineering (accessed November 2009).

16. School of Sustainable Engineering and the Built Environment, Arizona State University, http://engineering.asu.edu/sebe (accessed November 2009).

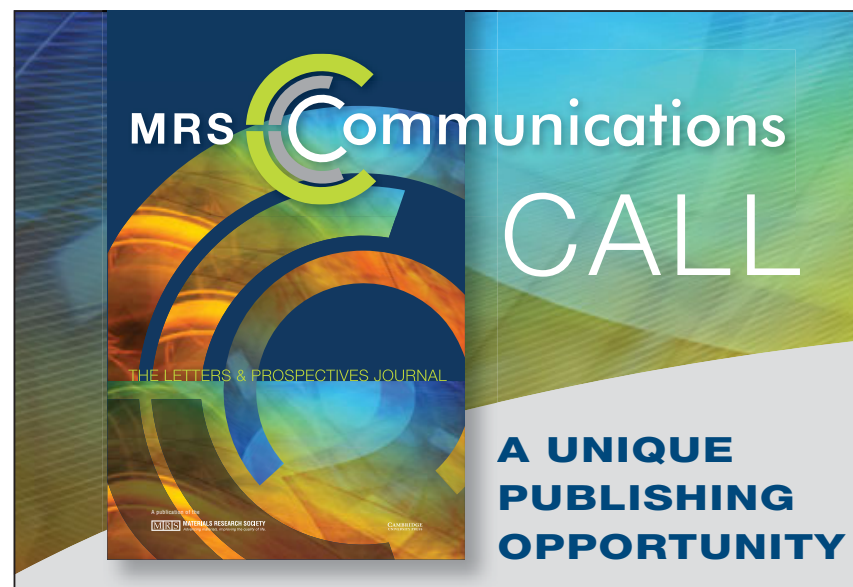

Manuscripts are being solicited for MRS Communications-a new full-color, high-impact journal focused on groundbreaking work across the broad spectrum of materials research.

Published jointly by the Materials Research Society (MRS) and Cambridge University Press, MRS Communications offers a rapid but rigorous peer-review process and time to publication. An aggressive production schedule will bring your article to online publication and a global audience within a target 14-day process from acceptance.

Hosted on the cutting-edge Cambridge Journals Online (CJO) platform, the journal features a robust suite of author and reader services, as well as an immediate reader/subscriber base including almost 16,000 MRS members and over 2,500 academic, industrial and government libraries worldwide.

Major article types for MRS Communications include:

\section{Research Letters}

Ultra-Rapid Communications

Prospectives Articles

Editorials

Commentaries

Correspondence

Prospectives Articles are a unique feature of this journal, offering succinct and forward-looking reviews of topics of interest to a broad materials research readership. For more information about the journal and/or these major article types, visit www.mrs.org/mrc or email mrc@mrs.org.
Manuscripts are solicited in the following topical areas, although submissions that succinctly describe groundbreaking work across the broad field of materials research are encouraged.

- Biomaterials and biomimetic materials

- Carbon-based materials

- Complex oxides and their interfaces

- Materials for energy storage, conversion and environmental remediation

- Materials for nanophotonics and plasmonic devices

- Theory and simulation of materials

- Mechanical behavior at the nanoscale

- Nanocrystal growth, structures and properties, including nanowires and nanotubes

- Nanoscale semiconductors for new electronic and photonic applications

- New materials synthesis, templating and assembly methods

- New topics in metals, alloys and transformations

- Novel and in-situ characterization methods

- Novel catalysts and sensor materials

- Organic and hybrid functional materials

- Quantum matter

- Surface, interface and length-scale effects on materials properties

For manuscript submission instructions, please visit www.mrs.org/mrc-instructions. 